\title{
An Exploration on the "Positioning" of Tutors in Undergraduate Tutorial System
}

\author{
Haijing Zuo \& Qingdong Yu \\ Department of Agriculture, Dezhou University, Dezhou 253000, China \\ E-mail: zhjss@126.com
}

Received: March 25, 2011 Accepted: April 25, $2011 \quad$ doi:10.5539/ass.v7n9p255

\begin{abstract}
The implementation of undergraduate tutorial system in colleges is a new tendency for the reform of college teaching system, and also a new trial for the reform of college management system. In order to ensure the successful implementation of undergraduate tutorial system, the position of tutors turns to be the key. For this issue, authors make an in-depth analysis from tutors' qualities, responsibilities, methods of guidance, and the incentive system of tutorial system, hoping to advance useful references for improving and perfecting the system.
\end{abstract}

Keywords: Connotations of tutorial system, Connotations of tutors, Positioning of tutors, Incentive system

\section{Introduction}

The undergraduate tutorial system is a newly-created system between teachers and students as a matter of fact. It is an institutional arrangement and also an institutional constraint. The so-called "institutional arrangement" means a newly-created platform for communication and exchange between teachers and students, offering a new way for students learning and creating. The so-called "institutional constraint" means dual constraints on teachers and students due to the implementation of tutorial system, and the constraints are mainly imposed on teachers. Most practices of tutorial system in colleges show that the position of tutors is the key for the success of tutorial system both theoretically and practically. Only by defining tutors' qualities, responsibilities, and methods of teaching based on a high standard, plus reasonable and effective incentive system, can it guarantee a positive operation of undergraduate tutorial system.

\section{Connotations of tutorial system}

The undergraduate tutorial system means that professional teachers in colleges take the responsibility of tutors, providing suggestions and guidance for students' learning, thinking, living, communication, and career planning. Meanwhile, professional teachers, as tutors, should assist and cooperate with student counselors in work. Connotations of undergraduate tutorial system should include two aspects. First, professional teachers should play a leading role in education. Second, students should behave as the main subjective during their growing and leaning process. The second aspect means that students must deal with learning and living activities seriously. Under the guidance of professional teachers, students can achieve the active and independent leaning, fulfilling the purpose of comprehensive development and personality development (Jinong Liu, 2010).

The undergraduate tutorial system, as an effective solution to the contradiction of "mass production" and "individual needs", organically combines the universality of undergraduate education and the targeted training objectives, being a useful supplement for regular school education.

\section{Connotations of tutors}

Yu Han, an ancient Chinese litterateur, said: "A teacher is to convey knowledge and answer questions." In the undergraduate tutorial system, professional teachers are college students' life mentors and close friends. In recent years, colleges' management mode of "educating people by teaching, educating people by management, and educating people by serving" fully emphasizes teachers' awareness of educating people, and sense of mission and responsibility. Teachers should regard teaching and educating people as sacred responsibility and obligation. In the past, most teachers only focus on conveying knowledge, but neglect the ultimate purpose of teaching, namely, educating people. On other words, their awareness of educating people is weak. Tutors in the tutorial system mean to personalize the education, specify the targets, and integrate the teaching and the educating. 
Meanwhile, tutors can get close to students during the process of tutoring, and integrate the transfer of knowledge into the directives of life by knowing students' minds and needs, further improving the quality of teaching.

\section{Positioning of tutors}

\subsection{The quality of tutors}

(1) Tutors are professional teachers with morals and professional competency.

(2) Tutors must hold a firm and correct political orientation, love the motherland, and support the leadership of the Communist Party and the socialist system; be loyal to the education cause of the Party, follow the professional ethics of teachers, teaching tirelessly with noble manners.

(3) Tutors must possess high-level professional knowledge and reasonable knowledge structure, be familiar with laws of education, and be capable of offering professional directions for students.

(4) Tutors should be selected from professional teachers with Master Degree or senior titles after necessary training.

\subsection{Responsibility of tutors}

The responsibility of tutors basically includes five aspects: ideology, professional assistance, living guidance, psychological help, and career planning (Fandong Zeng, 2004).

(1) In terms of ideology, tutors should help students to establish a correct outlook on life and values, to consciously resist the erosion of evil ideas, and to grow into high-quality talents, useful to the motherland and the society.

(2) In learning, tutors should help students to understand their potentials and personalities, teach them how to study well and how to get the ability of creative learning. Help students to correct learning attitudes, stimulate their enthusiasm for study, and improve the quality of learning.

(3) In daily life, tutors can be a guide. Help students to adapt to college life with parent love. Help them to establish life goals, correct attitudes to life, develop good habits, and improve the quality of life.

(4) In terms of psychology, tutors should keep effective communication with students, listen to their hearts, help them to solve problems and confusions in learning and living, eliminate kinds of psychological problems and mental disorders timely, reduce psychological pressures, help them to establish optimistic and positive attitudes to life, and improve their abilities of dealing with frustrations.

(5) For career planning, tutors can help students to know their abilities and interests better, help them to make correct decisions for careers, improve students' abilities of adapting to professions, and prepare them for employment.

\subsection{Tutoring measures}

Tutors can help students by following ways (Lijuan Wu, 2010):

(1) Group tutoring: Tutors gather all students and give general face-to-face direction by means of lectures or meetings.

(2) Individual tutoring: Tutors give special directions to students by solo conversations considering different personalities of students.

(3) Online tutoring: Tutors can supply online chat directions for students who refuse to face tutors in person due to psychological problems or characters.

(4) Telephone tutoring: Tutors can give parent-like directions to students by telephone for some burst problems or psychological problems

(5) Tutoring by letters: Tutors can communicate with students effectively by exchange of letters. Listen to their thoughts, help them to solve problems in learning and living, eliminate kinds of psychological problems timely, and reduce psychological pressures.

\section{Incentive mechanism for undergraduate tutorial system}

In most colleges, the supervision system and incentive mechanism for undergraduate tutorial system are imperfect, such as the ineffective incentive methods, assessing the teaching by quantity, insufficient direction, without fundamental evaluation. As a result, some tutors lack of enthusiasm for the tutorial system. And few tutors even completely drop the responsibility except the title. Therefore, it is urgent to amend and regulate the tutorial system according to actual situations. 


\subsection{Grasp the principles of tutor incentive mechanism}

(1) The principle of combining spiritual incentive with material incentive

College teachers have a strong sense of independency. They pay more attention to self-realization. Therefore, spiritual incentive should be more lasting and effective in a sense. However, under the circumstance of market economy, knowledge is an important part of capital. To capitalize knowledge is also an important incentive factor. College teachers possess super professional techniques after a long period of study. Higher income can motivate their enthusiasm for tutoring. Therefore, it is very important to apply the principle of combining material incentive and spiritual incentive to practice.

(2) The principle of emphasizing on society and fairness

In designing the undergraduate tutorial system, colleges should not only consider the situations of colleges, but also think about the social and psychological influences, making best use of social comments as much as possible. Meanwhile, take full account of conditions of teachers and other related staff, and make sure that the incentives are equal for them all. Treat all teachers equally.

(3) The principle of differentiation and diversity

Because of huge differences of students, and the diversified effects of social development and external changes on tutors, the incentive measures should be flexible. The same incentive measure will repress teachers' enthusiasm. Therefore, we should adopt different incentives for different student groups, or assess the grades of tutors by comprehensive evaluation, in order to improve their enthusiasm for tutoring, satisfying tutors' needs for self-esteem and self-realization.

(4) The principle of transparency

The undergraduate tutorial system should be commitment to transparent policy constitution, transparent incentive procedures, and transparent incentive results. Only by means of the three aspects, can the incentive policy be vital, and incentive behavior be encouraging, achieving the sustainable development of undergraduate tutorial system.

\subsection{Effective measures for the tutor incentive mechanism}

The undergraduate tutorial system needs a scientific incentive mechanism and effective incentive measures.

(1) Implement the tutor appointment mechanism

A complete implementation of tutor appointment mechanism is a fundamental measure for an incentive mechanism. Set up positions for needs and appoint tutors. Make competitive rules for positions. Evaluate the work of tutors and achieve contract managements. Change the tutor management system from title management to position management. Finally, appointed tutors treat their students carefully and other teachers have to win competitions by improving themselves in order to become tutors. Thus form a dynamic virtuous incentive cycle and enhance the tutors' spirits of dedication to positions.

(2) Establish a strict and reasonable system for assessment and evaluation

Assessment is an important part of scientific management. To make an accurate assessment of tutors' performances is an important way for encouraging teachers. The assessment needs reasonable standards. Take students' satisfaction degree and success as the baseline and design scientific and dynamic indexes and contents for the assessment. And set up serious scientific procedures. The assessment should be mainly based on quantities, together with quality. Insist to the principle of flexibility and reality. Assessment results should be publicized and timely feedback to tutors. Awards should be given in time, no halo effect or taking in turn. Adopt different kinds of rewards based on different standards. And the incentives should be accurate and fair.

(3) Handle the relationship of different incentives

In the incentive mechanism, we should pay attention to handle four kinds of relationships: 1) The relationship of material incentive and spiritual incentive. Impose equal importance to material incentive and spiritual incentive. Emphasize on the combination of the two and never neglect any of them. 2) The relationship of internal incentive and external incentive. Use internal incentive to strengthen college teachers' self-awareness and initiatives, with the assistance of external incentive. 3) The relationship of positive incentive and negative incentive. Highlight the positive incentive for tutors and make full use of excellent examples. Use negative incentive to warn. 4) The relationship of fair incentive and inclined incentive. Under normal conditions, incentives should be fair and just. However, in order to achieve specific purposes, some inclined incentives, such as special and different incentives, are necessary under certain conditions (Shuisheng Chen \& Huanrong Li, 2005). 


\section{Tutors should handle two kinds of relationships properly}

\subsection{Properly handle the relationship of tutors and teachers}

There are huge differences between tutors and teachers. Tutors should be complex talents, with complex knowledge, professions, and thinking. Teachers merely possess common knowledge and specialty. Besides, tutors should take full responsibilities for students in educating and teaching. They not only teach but also educate the students. They teach generally and individually, considering students' common characteristics and personality development. Therefore, examine the quality of tutors strictly. Tutors must be teachers, but teachers are not necessary good tutors.

\subsection{Properly handle the relationship of tutors and counselors}

Tutors should combine their work with counselors' work organically. Tutors are mainly responsible for giving directions for students' morals, learning, life, psychology, and career planning. Individual guidance is the chief part. Counselors focus on daily management. They organize students to design and develop activities. They give ideological helps to students. Focusing on the same objects, the work of tutors and counselors has overlapped part and also different part. Only by properly handle the relationship of tutors and counselors, can we ensure the normal operation of undergraduate tutorial system.

\section{References}

Chen, Shuisheng \& Li, Huanrong. (2005). An exploration of the motivation of teachers in institutions of higher education in China. Journal of Wuyi University (Social Sciences Edition), No.5.

Liu, Jinong. (2010). On undergraduate tutorial system. Modern Enterprise Education, No.4.

Wu, Lijuan. (2010). Investigation and research on undergraduate tutorial system implementation. Journal of Shenyang Normal University, No.1.

Zeng, Fandong. (2004). Thoughts on undergraduate tutorial system. Forum on Contemporary Education, No.10. 